\title{
Impact of vertebrate probiotics on honeybee yeast microbiota and on the course of nosemosis")
}

\author{
ANETA A. PTASZYŃSKA, GRZEGORZ BORSUK*, WIESŁAW MUŁENKO, JOANNA WILK \\ Department of Botany and Mycology, Institute of Biology and Biochemistry, Faculty of Biology and Biotechnology, \\ Maria Curie-Skłodowska University, Akademicka 19, 20-033 Lublin, Poland \\ *Department of Biological Basis of Animal Production, Faculty of Biology and Animal Breeding, \\ University of Life Sciences in Lublin, Akademicka 13, 20-950 Lublin, Poland
}

Ptaszyńska A. A., Borsuk G., Mułenko W., Wilk J.

Impact of vertebrate probiotics on honeybee yeast microbiota and on the course of nosemosis

Summary

The natural intestine microbiota of honeybees is dominated by Gram-negative bacteria from such families as: Enterobacteriaceae, Alcaligenaceae and Pseudomonadaceae, less numerous are Gram-positive bacteria, yeasts and other fungi. Our research was focused on the impact of commercial vertebrae probiotics, on honeybees' intestine yeast number, hemolymph lysozyme activity and nosemosis development. The diet of honeybees was supplemented with two vertebrate probiotics recommended in beekeeping management. The former consisted of Lactobacillus casei, L. plantarum, Saccharomyces cerevisiae, and Rhodopseudomonas palustris. The latter consisted of $L$. acidophilus, $L$. delbrueckii, and Bifidobacterium bifidum.

Yeasts isolated from honeybees' intestine and detected in our research belonged to two genera: Candida and Saccharomyces. The average number of yeast Colony Forming Units (CFUs) in uninfected honeybees fed only sugar syrup was $3850( \pm 400.33)$ and after Nosema spp. infection the number rose to $19500( \pm 1644.40)$ per one honeybee. The addition of a probiotic decreased the number of detected yeast CFUs in both groups of infected and uninfected honeybees.

Nosema infection did not affect lysozyme activity; therefore it was the administration of probiotics that had the main impact on the rise of lysozyme level. Most likely very vivid probiotic bacteria were treated as invaders by honeybees' immune defense, which resulted in almost $\mathbf{4 0 \%}$ rise observed in lysozyme activity. Furthermore, probiotic supplementation accelerated the nosemosis development even twofold. Probably, increased acidity of the honeybees' intestine, which is a consequence of the uncontrolled growth of lactic acid bacteria, created conditions favorable to faster nosemosis development. Therefore, every administration of diet supplements with live microorganisms whose impact on honeybees biology and physiology is not well studied should be carried out with the greatest caution.

Keywords: Apis mellifera, nosemosis, yeast, Candida, Saccharomyces, diet supplements, lysosyme activity

Vital pollinators whose role in ecosystems can hardly be overestimated, honeybees suffer from numerous illnesses, among which varroatosis and nosemosis seem most dangerous. Unfortunately, there is no cure that could resolve these grave honeybee health problems. Therefore, a great number of various kinds of diet supplements to help combat these illnesses are recommended for honeybee feeding. These include commercial probiotics whose primarily composition is based on the bacteria from the Lactobacillus genus.

Symbiotic microbiota prevent the growth of pathogenic species by competing for nutrition and attachment sites to the epithelium of the intestine. The microorgan-

1) This research was supported by the Individual Research Grant of Deputy ViceChancellor for Research and International Relations of UMCS (Lublin, Poland). isms associated with the honeybee come from pollen consumption or through contact with older workers (e.g. trophallaxis). Bacteria from the Lactobacillus (LAB) genus are some of the most important intestinal symbionts, and the LAB members most frequently isolated from honeybees are: Lactobacillus kunkeei, L. plantarum, L. pentosus, L. fermentum, L. floricola, L. acidophilus and L. johnsonii (4, 12, 27, 41, 42, 44). Honeybee Lactobacillus bacteria, as all members of this genus, produce a short chain fatty acids which can be absorbed through the rectal wall and provide additional nutrition. Furthermore, bacteria from the Lactobacillus and Bifidobacterium genera which inhabit honeybees' crop play a very important role in the production of honey and beebread $(8-11,13,24$, $25,43,44)$. 
Therefore, in beekeeping management as well as in other animal husbandry and welfare, some diet supplements containing probiotic bacteria are recommended. One of such commercial dietary supplements consists of Gram-positive bacteria (Lactobacillus casei, Lactobacillus plantarum), Gram-negative bacteria (Rhodopseudomonas palustris) and yeasts (Saccharomyces cerevisiae). The presence of LAB bacteria in such preparations is obvious, due to their widespread presence in the intestinal tract and wellstudied beneficial effects, but the addition of yeast to honeybees' diet is rather controversial. Some intestinal yeasts common among higher animals have a trophic effect because of providing a source of B vitamins, proteins, trace minerals and essential amino acids, and therefore can be treated as probiotic microorganisms for mammals. But healthy free flying honeybees have only few yeasts if any; moreover some studies suggest that yeast can be considered as honeybees' stress indicators $(7,16-22)$. Furthermore, the addition of yeast to honeybees' diet leads to damage of the midgut epithelial layer (28). Incidentally, Nosema spp. infection has a similarly devastating effect on honeybees' intestines, which nowadays has been thoroughly studied by many researches (e.g. 13-15, 30-32).

Therefore, this study aimed at determining the effect of commercial vertebrae probiotics recommended by their producers as beneficial in beekeeping management on honeybees' yeast microbiota, hemolymph lysozyme activity, and furthermore on the nosemosis course.

\section{Material and methods}

Cage experiments. Two independent cage experiments were conducted in July and August, 2014. To obtain 1-day-old healthy honeybees, combs with brood originating from one queen bee were taken in the $20^{\text {th }}$ day of the development, put in an air-conditioned chamber, and kept at the constant temperature of $35^{\circ} \mathrm{C}$, and the relative humidity of $60 \%$. Such honeybees were kept under the laboratory conditions in complete darkness $\left(30^{\circ} \mathrm{C} ; \mathrm{H}=65 \%\right)$, in wooden cages settled by 40 specimens.

On the third day after emerging, honeybees were N. ceranae infected according to the methodology described by Forsgren and Fries (13), and after three more days - i.e. from the $6^{\text {th }}$ day till the end of experiment (24 days after emerging) - they were fed with sugar-water syrup supplemented with two commercial probiotics. The former $\left(1^{\text {st }}\right.$ Prob) consisted of L. casei, L. plantarum $-5.0 \times 10^{6}$ $\mathrm{CFU} / \mathrm{ml}$; Saccharomyces cerevisiae - 5.0 × $10^{6} \mathrm{CFU} / \mathrm{ml}$ and Rhodopseudomonas palustris - abundant in $1 \mathrm{ml}$ (cane molasses) and was added to water-sucrose (1:1) syrup to a final concentration of Lactobacillus cells of $5 \times 10^{3}$ CFU $/ \mathrm{ml}$. The latter ( $2^{\text {nd }}$ Prob) consisted of L. acidophilus - $6.0 \times 10^{9} \mathrm{CFU} / \mathrm{ml}$, L. delbrueckii - $4.0 \times 10^{9} \mathrm{CFU} / \mathrm{ml}$, Bifidobacterium bifidum $-6.0 \times 10^{9} \mathrm{CFU} / \mathrm{ml}$, and was added to water-sucrose $(1: 1)$ syrup to a final concentration of Lactobacillus cells of $5 \times 10^{3} \mathrm{CFU} / \mathrm{ml}$.
At the end of each experiment, the number of $N$. ceranae spores was counted, and fecal samples were collected to culture intestinal yeast. Moreover, hemolymph was collected to measure lysozyme activity.

Nosema ceranae spores counting. From every group, three independent samples per 10 honeybees were grounded in $10 \mathrm{ml}$ of sterile water, after which the homogenates were smeared on a microscope slide for examination. For each spore suspension, averages of 2 estimates of intensity were used. The estimation of $N$. ceranae spores number per bee was accomplished using Olympus BX 61 light microscope and a haemocytometer $(15,23)$.

Estimation of yeast CFU. From each group two repeats per 10 honeybees were surface sterilised in $70 \%$ ethanol and were aseptically and delicate pressed into discharged feces into one sterile eppendorf tube. The collected feces were mixed to obtain a homogenate solution. After that, $150 \mu \mathrm{L}$ of sampled feces was resuspended in $150 \mu \mathrm{L}$ of sterile 0.6 $\mathrm{NaCl}$ solution. Next, $100 \mu \mathrm{L}$ of such suspension was spread in duplicate on Petri dishes containing Sabouraud dextrose agar with chloramphenicol and gentamycin, and incubated for 5 days at $30^{\circ} \mathrm{C}$. The $\mathrm{API}^{\circledR}$ strips-Yeasts (bio Mérieux Clinical Diagnostics) were used to differentiate fungi isolated from honeybees' intestinal tracts.

Hemolymph sampling and the measurement of lysozyme activity. Hemolymph from every ten individuals was collected in sterile conditions into sterile chilled Eppendorf tubes and immediately frozen at $-20^{\circ} \mathrm{C}$ until the lysozyme activity was measured.

Lysozyme activity in pooled hemolymph samples was determined by measurement of Microccocus lysodeicticus (M3770; Sigma) lytic zones on agar plates (29). Each well on the Petri dish was filled with $7 \mu \mathrm{L}$ of undiluted hemolymph samples, and after 24 hours incubation at $28^{\circ} \mathrm{C}$ the lytic zones were measured. Each hemolymph sample was tested in two repeats. Sterile saline solution was used as the negative control. The activity of lysozyme was calculated from a standard curve made with egg white lysozyme (EWL, EC 3.2.1.17; Sigma) and expressed as activity corresponding to activity of EWL solutions of known concentrations $(\mu \mathrm{g} / \mathrm{mL}$ of EWL).

Statistical analysis. The SAS software (33) using the ANOVA (a group effect was the experimental factor), the Student's t-test significant value, and the Tukey's HSD (honestly significant difference) test, were used to prepare the statistical analysis of the obtained data. The Sperman's correlation between numbers of the yeast CFUs and N. ceranae spores was calculated.

\section{Results and discussion}

Natural intestine microbiota of honeybees is dominated by Gram-negative bacteria from such families as: Enterobacteriaceae, Alcaligenaceae and Pseudomonadaceae; less numerous are Gram-positive bacteria, yeasts and other fungi. In our research, the culturing conditions allowed the detection of fungi that belonged to two genera: Candida and Saccharomyces. The average number of yeast CFUs in uninfected honeybees fed only sugar syrup was $3850( \pm 400.33)$ 


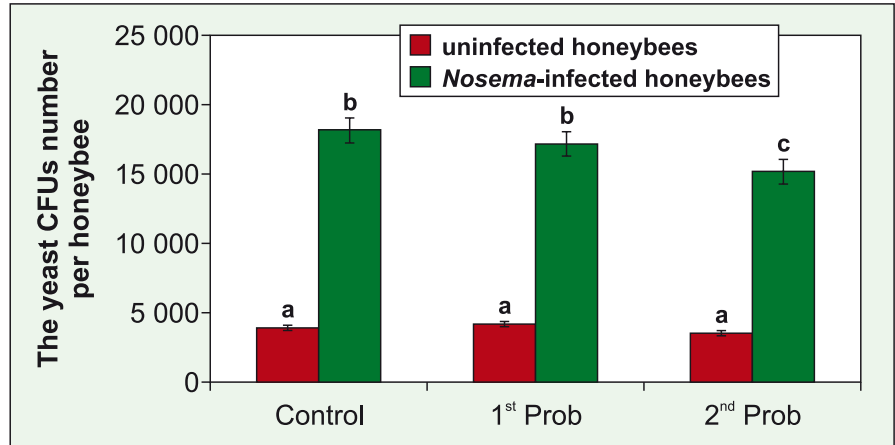

Fig. 1. The intestinal yeast CFU number detected in honeybees fed with commercial probiotics. Supplementation among the groups: Control (pure sugar syrup); $1^{\text {st }}$ Prob $\left(5 \times 10^{3}\right.$ of Lactobacillus CFU per $1 \mathrm{~mL}$ of sugar syrup, and $5 \times 10^{3}$ of Saccharomyces CFU per $1 \mathrm{~mL}$ of sugar syrup), $2^{\text {nd }}$ Prob $\left(5 \times 10^{3}\right.$ of Lactobacillus CFU per $1 \mathrm{~mL}$ of sugar syrup, and $5 \times 10^{3}$ of Bifidobacterium CFU per 1 mL of sugar syrup)

Explanation: a, b, c-different letters in columns indicate statistically significant differences among the groups $(p<0.05)$. Error bars represent standard deviation of data.

and after Nosema spp. infection the number rose to $19500( \pm 1644.40)$ per one honeybee (Fig. 1). The addition of a probiotic decreased the number of detected yeast CFUs in both groups of infected and uninfected honeybees. However, only the addition of $2^{\text {nd }}$ Prob had a significant impact on the yeast CFU number detected in N. ceranae infected honeybees. Most likely very vivid lactic acid bacteria, as there are in commercial probiotics, won the competition for nutrients and attachment sites with honeybees yeast microbiota. Insignificant differences obtained in the yeast CFU number detected after feeding honeybees with $1^{\text {st }} \mathrm{Prob}$ may be due to this supplement's composition in which yeast from the Saccharomoces genus were included. Nevertheless, the number of detected yeast CFUs was lower than in the control group (Fig. 1), which indicates that although yeast cells were added to honeybees' diet, they had to be partially digested.

Generally, yeast number was raised after exposure of honeybees to stressful factors: even keeping honeybees in cages, without a bee queen or the possibility of flying, increased the number of yeast CFUs (18-22). Therefore, data which indicated decrease in yeast CFUs number after feeding honeybees with commercial probiotics could be misunderstood as beneficial; but when comparing these data with the nosemosis development (Fig. 2), it is clear that the effect of commercial probiotics on the honeybee as a whole is disadvantageous. The increased acidity of the honeybees intestine, which is a consequence of the uncontrolled growth of lactic acid bacteria, might have created conditions favorable to faster nosemosis development (Fig. 2, Tab. 1), whose level was even two times higher among honeybees fed with commercial probiotics.

Nosema infection did not affect lysozyme activity. In honeybees groups fed pure sucrose syrup, the lysozyme activity was generally low (Fig. 3 control groups), much like in earlier studies $(3,14,26)$.

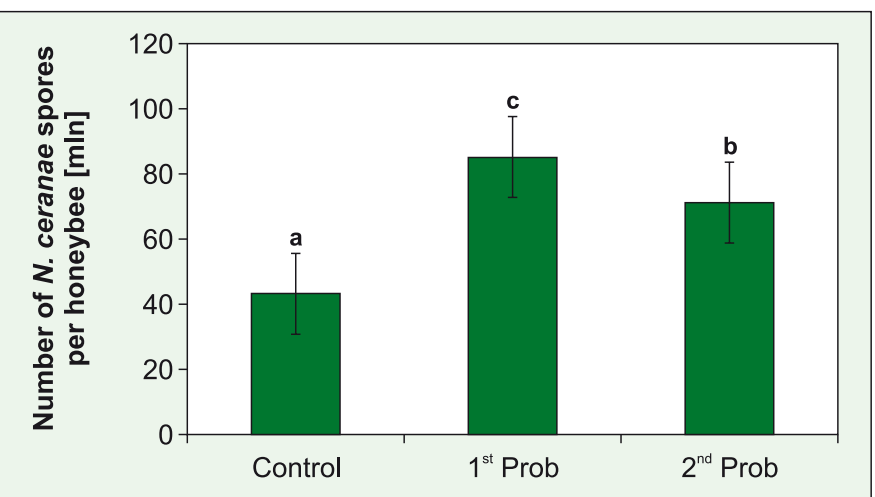

Fig. 2. The $N$. ceranae spores number detected in honeybees fed with commercial probiotics. Supplementation among the groups: control (pure sugar syrup); $1^{\text {st }}$ Prob $\left(5 \times 10^{3}\right.$ of Lactobacillus CFU per $1 \mathrm{~mL}$ of sugar syrup, and $5 \times 10^{3}$ of Saccharomyces CFU per $1 \mathrm{~mL}$ of sugar syrup), $2^{\text {nd }}$ Prob $\left(5 \times 10^{3}\right.$ of Lactobacillus CFU per $1 \mathrm{~mL}$ of sugar syrup, and $5 \times 10^{3}$ of Bifidobacterium CFU per $1 \mathrm{~mL}$ of sugar syrup)

Explanation: $\mathrm{a}, \mathrm{b}, \mathrm{c}-$ different letters in columns indicate statistically significant differences among the groups $(p<0.05)$. Error bars represent standard deviation of data.

Tab. 1. The Sperman's correlation between numbers of the yeast CFU and $N$. ceranae spores (*significant correlations)

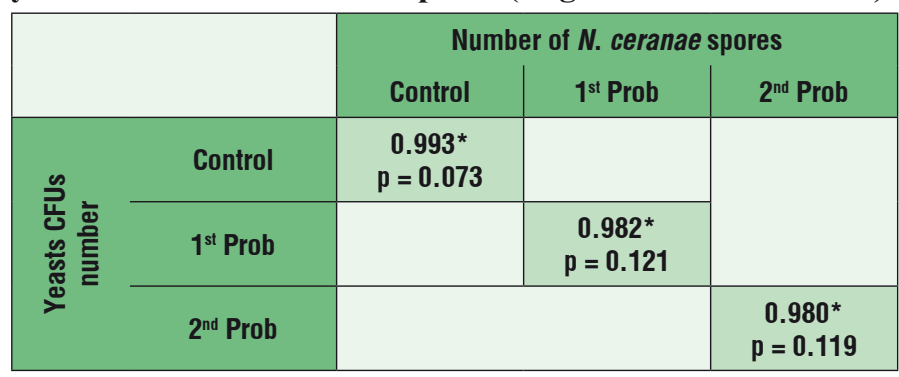

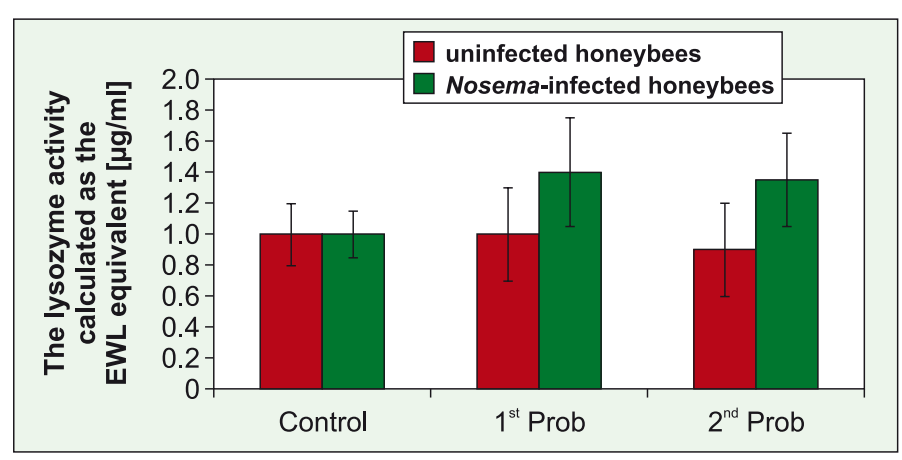

Fig. 3. The lysozyme activity level in the hemolymph of honeybees fed with commercial probiotics calculated as the EWL equivalent $(\mu \mathrm{g} / \mathrm{mL})$. Supplementation among the groups: Control (pure sugar syrup); $1^{\text {st }}$ Prob $\left(5 \times 10^{3}\right.$ of Lactobacillus CFU per $1 \mathrm{~mL}$ of sugar syrup, and $5 \times 10^{3}$ of Saccharomyces CFU per $1 \mathrm{~mL}$ of sugar syrup), $2^{\text {nd }}$ Prob $\left(5 \times 10^{3}\right.$ of Lactobacillus CFU per $1 \mathrm{~mL}$ of sugar syrup, and $5 \times 10^{3}$ of Bifidobacterium CFU per $1 \mathrm{~mL}$ of sugar syrup). Error bars represent standard deviation of data

Therefore, it was the administration of probiotics that had the main impact on the rise of lysozyme level. Lysozyme activity (Fig. 3) reached highest value for Nosema-infected honeybees fed with probiotic bacteria. Lysozyme degrade the peptidoglycan shell of Gram-positive bacteria (27), as do the microorganisms 
from the Lactobacillus genus used in the experiments as commercial probiotics. Probably rapid nosemosis development accelerated by the commercial probiotic feeding (Fig. 2) led to honeybees' grievous intestine degeneration. Local damage of these protective barriers might have facilitated penetration of bacteria into honeybees' hemocoel were they were treated as invaders, which activated the lysozyme synthesis.

Invertebrates have diverse anti-infection mechanisms that vary even within phylum among representatives of different orders. The immune mechanisms of an individual honeybee are strongly reduced in comparison to other insects (11). Honeybee foragers have a reduced hemocyte number in comparison to other insects and a significant decline in the capability to form nodules in response to bacterial infections $(1-3,5,32,34,36-40,45-47)$. Maintaining immune competence in the individual specimen, although very important, is associated with a loss of energy (34) and all these "reductions" represent a honeybee colony-level strategy with restricted hygienic behavior and highly antibacterial nest environment $(6,7,35)$. The commercial probiotics examined in the present study obviously did not increase honeybees' fitness; on the contrary, their addition to bees' diet resulted in intestine malfunctions and created conditions favorable to development of other intestinal illnesses, such as nosemosis. Furthermore, very vivid microorganisms from those probiotics were treated as invaders, which resulted in raising such energy cost processes as defense mechanism activation, manifested as lysozyme over synthesis. That all additionally increased honeybees' energy demands and led to honeybees' malnutrition and higher mortality rate among foragers. Therefore, every administration of diet supplements with live microorganisms whose impact on honeybees' biology and physiology is not well studied should be carried out with the greatest caution, and in the future probiotics should be developed that are designated specifically for honeybees' feeding.

\section{References}

1. Amdam G. V., Simoes Z. L., Hagen A., Norberg K., Schroder K., Mikkelsen O., Kirkwood T. B., Omholt $S$. W.: Hormonal control of the yolk precursor vitellogenin regulates immune function and longevity in honeybees. Exp. Geront. 2004, 39, 767-773

2. Andrejko M., Zdybicka-Barabas A., Cytryńska M.: Diverse effects of Galleria mellonella infection with entomopathogenic and clinical strains of Pseudomonas aeruginosa. J. Invertebr. Pathol. 2014, 115, 14-25.

3. Antúnez K., Martin-Hernandez R., Prieto L., Meana A., Zunino P., Higes M. Immune suppression in the honey bee (Apis mellifera) following infection by Nosema ceranae (Microsporidia). Environ. Microbiol. 2009. doi:10.1111/ j.1462-2920.2009.01953x

4.Audisio M. C., Torres M. J., Sabaté D. S., Ibarguren C., Apella M. C.: Properties of different lactic acid bacteria isolated from Apis mellifera L. bee-gut. Microbiol. Res. 2011, 166, 1-13, http://dx.doi.org/10.1016/j.micres. 2010.01.003

5. Bedick J. C., Tunaz H., Nor Aliza A. R., Putnam S. M., Ellis M. D., Stanley $D . W$.: Eicosanoids act in nodulation reactions to bacterial infections in newly emerged adult honey bees, Apis mellifera, but not in older foragers. Comp. Biochem. Phys. C. 2001, 130, 107-117.

6. Borsuk G., Strachecka A., Olszewski K., Paleolog J.: The interaction of worker bees which have increased genotype variance, Part 2. cage tests of sugar syrup collecting and mortality. J. Apicult. Sci. 2011b, 55, 59-65.
7. Borsuk G., Strachecka A., Olszewski K., Paleolog J.: The interaction of worker bees with increased genotype variance, Part 1. field tests of sugar syrup collection and storage. J. Apicult. Sci. 2011a, 55, 53-58.

8. Bradley T. J.: Active transport in insect recta. J. Exp. Biol. 2008, 211, 835-836. 9.El-leithy M., El-sibael K.: Role of microorganisms isolated from bees, its ripening and fermentation of honey. Egypt. J. Microbiol. 1992, 75, 679-681.

10. Evans J. D., Armstrong T.-N.: Antagonistic interactions between honey bee bacterial symbionts and implication for disease. BMC Ecology 2006, 6, 4.

11. Evans J. D., Aronstein K., Chen Y. P., Hetru C., Imler J. L., Jiang H., Kanost M., Thompson G. J., Zou Z., Hultmark D.: Immune pathways and defence mechanisms in honeybees Apis mellifera. Insect Mol. Biol. 2006, 15, 645-656.

12. Evans J. D., Lopez D. L.: Bacterial probiotics induce immune response in the honey bee (Hymenoptera: Apidae). J. Econ. Entomol. 2004, 97, 752-756.

13. Forsgren E., Fries I.: Comparative virulence of Nosema ceranae and Nosema apis in individual European honey bees. Vet. Parasitol. 2010, 170, 212-217.

14. Fries I.: Nosema ceranae in European honey bees (Apis mellifera). J. Invertebr. Pathol. 2010, 103, S73-S79.

15. Fries I., Chauzat M.-P., Chen Y.-P., Doublet V., Genersch E., Gisder S., Higes M., Mcmahon D. P., Martín-Hernández R., Natsopoulou M., Paxton R. J., Tanner G., Webster T. C., Williams G. R.: Standard methods for nosema research, [in:] Dietemann V., Ellis J. D., Neumann P. (Eds): The Coloss Beebook: Vol. II: Standard methods for Apis mellifera pest and pathogen research. J. Apic. Res. 2013, 51, http://dx.doi.org/10.3896/IBRA.1.52.1.14

16. Gilliam M.: Are yeasts present in adult worker honey bees as a consequence of stress? Ann. Enlomal. Soc. Am. 1973, 66, 1176.

17. Gilliam M., Figer S.: Diseases, pests, and normal microflora of honeybees, Apis mellifera, from feral colonies. J. Invertebr. Pathol. 1991, 58, 286-289.

18. Gilliam M., Prest D. B.: Fungi isolated from the intestinal contents of foraging worker honey bees, Apis mellifera. J. Invertebr. Pathol. 1972, 20, 101-103.

19. Gilliam M., Taber S.: Diseases, pests, and normal microflora of honeybees Apis mellifera, from feral colonies. J. Invertebr. Pathol. 1991, 58, 286-289.

20. Gilliam M., Valentine D. K.: Bacteria isolated from the intestinal contents of foraging worker honey bees, Apis mellifera: the genus Bacillus. J. Invertebr. Pathol. 1976, 28, 275-276.

21. Gilliam M., Valentine D. K.: Enterobacteriaceae isolated from foraging worker honey bees, Apis mellifera. J. Invertebr. Pathol. 1974, 23, 38-41.

22. Gilliam M., Wickerham L. J., Morton H. L., Martin R. D.: Yeasts isolated from honey bees, Apis mellifera, fed 2,4-D and antibiotics. J. Invertebr. Pathol. 1974, 24, 349-356

23. Hornitzky M.: Nosema Disease - Literature review and three surveys of beekeepers - Part 2. Rural Industries Research and Development Corporation 2008, Pub. No. 08/006

24. Lindstrom A., Korpela S., Fries I.: The distribution of Paenibacillus larvae spores in adult bees and honey and larval mortality, following the addition of American foulbrood diseased brood or spore-contaminated honey in honey bee (Apis mellifera) colonies. J. Invertebr. Pathol. 2008, 99, 82-86.

25. Martinson V., Danforth B. N., Minckley R., Rueppell O., Tingek S., Moran N.: A simple and distinctive microbiota exclusively associated with honey bees and bumble bees. Mol. Ecol. 2011, 20, 619-628. http://onlinelibrary.wiley. com/doi/10.1111/j.1365-294X.2010.04959.x/full

26. Masschalck B., Michiels C. W.: Antimicrobial properties of lysozyme in relation to foodborne vegetative bacteria. Crit. Rev. Microbiol. 2003, 29, 191-214.

27. McFrederick O. S., Wcislo W. T., Taylor D. R., Ishak H. D., Dowd S. E., Mueller $U$. G.: From environment or kin: whence do bees obtain acidophilic bacteria? Mol. Ecol. 2012, 21, 1754-1768.

28. Mirjanic G., Tlak-Gajger I., Mladenovic M., Kozaric Z.: Impact of different feed on intestine health of honey bees. XXXXIII International Apicultural Congress, Apimondia, Kyiv, Ukraine, 29.09-04.10 2013, Scientific Program: Oral presentation abstracts \& poster list, p. 113.

29. Mohrig W., Messner B.: Immunreaktionen bei Insekten. I. Lysozym als grundlegender antibakterieller Faktor im humoralen Abwehrmechanismus der Insekten. Biol. Zbl. 1968, 87, 439-447.

30. Ptaszyńska A. A., Borsuk G., Mułenko W., Demetraki-Paleolog J.: Differentiation of Nosema apis and Nosema ceranae spores under Scanning Electron Microscopy (SEM). J. Apic. Res. 2014, 53, 537-544 DOI: 10.3896/IBRA. 1.53.5.02

31.Ptaszyńska A. A., Borsuk G., Woźniakowski G., Gnat S., Małek W.: Loopmediated isothermal amplification (LAMP) assays for rapid detection and differentiation of Nosema apis and N. ceranae in honeybees. FEMS Microbiol. Lett. 2014, 357, 40-48, DOI: 10.1111/1574-6968.12521.

32. Ptaszyńska A. A., Borsuk G., Zdybicka-Barabas A., Cytryńska M., Małek W. Are commercial probiotics and prebiotics effective in the treatment and prevention of honeybee nosemosis C? Parasitol. Res. 2015, DOI: 10.1007/ s00436-015-4761-z

33. SAS/STAT Users Guide release 9.13, Cary, NC, Statistical Analysis System Institute. 2014 
34.Schmid M. R., Brockmann A., Perk C. W., Stanley D. W., Tautz J.: Adult honeybees (Apis mellifera L.) abandon hemocytic, but not phenoloxidase-based immunity. 2008, 54, 439-444.

35. Schmid-Hempel P.: Variation in immune defence as a question of evolutionary ecology. Proceed. Royal Soc. Lond. B. 2003, 270, 357-366.

36. Strachecka A., Borsuk G., Olszewski K., Paleolog J., Gagoś M., Chobotow J. Nawrocka A., Gryzińska M., Bajda M.: The effect of amphotericin B on the lifespan, body-surface protein concentrations and DNA methylation level of the honey bees (Apis mellifera). J. Apic. Sci. 2012, 56, 107-113

37. Strachecka A., Borsuk G., Paleolog J., Olszewski K., Chobotow J.: The body surface compounds in Buckfast and Caucasian workers (Apis mellifera). J. Apic. Sci. 2014, 58, 5-15.

38. Strachecka A. J., Gryzinska M. M., Krauze M., Grzywnowicz K.: Profile of the body surface proteolytic system in Apis mellifera queens. Czech J. Anim. Sci. 2011, 56, 15-22.

39. Strachecka A., Olszewski K., Paleolog J.: Curcumin improves the health state of Apis mellifera workers to a surprisingly large extent. J. Apic. Sci. 2015, 59.

40. Strachecka A. J., Paleolog J., Grzywnowicz K.: The surface proteolytic activity in Apis mellifera. J. Apic. Sci. 2008, 52, 49-56.

41. Tajabadi N., Mardan M., Manap M. Y. A., Mustafa S.: Molecular identification of Lactobacillus spp. isolated from the honey comb of the honey bee (Apis dorsata) by 16 S rRNA gene sequencing. J. Apic. Res. 2013, 52, 235-241. DOI: 10.3896/IBRA.1.52.5.10
42. Tajabadi N., Mardan M., Manap M. Y. A., Shuhaim M., Meimandipour A., Nateghi L.: Detection and identification of Lactobacillus bacteria found in the honey stomach of the giant honeybee Apis dorasta. Apidologie 2011, 42, 642-649.

43. Vásquez A., Forsgren E., Fries I., Paxton R. J., Flaberg E., Szekely L., Olofsson T. C.: Symbionts as major modulators of insect health: lactic acid bacteria and honeybees. PLoS ONE 2012, 7, e33188. DOI: 10.1371/journal.pone.0033188. t002

44. Vásquez A., Olofsson T. C.: The lactic acid bacteria involved in the production of bee pollen and bee bread. J. Apic. Res. 2009, 48, 189-195 DOI: 10.3896/ IBRA.1.48.3.07

45.Zdybicka-Barabas A., Cytryńska M.: Apolipophorins and insects immune response. ISJ-Inverteb. Surv. J. 2013, 10, 58-68.

46. Zdybicka-Barabas A., Cytryńska M.: Phenoloxidase activity in hemolymph of Galleria mellonella larvae challenged with Aspergillus oryzae. Ann. UMCS Sec. C (Biologia) 2010, 65, 49-57.

47.Zdybicka-Barabas A., Mak P., Jakubowicz T., Cytryńska M.: Lysozyme and defense peptides as suppressors of phenoloxidase activity in Galleria mellonella. Arch. Insect. Biochem. Physiol. 2014, 87, 1-12.

Corresponding author: Dr. Aneta A. Ptaszyńska, PhD, Akademicka 19, 20-033 Lublin, Poland; e-mail: aneta.ptaszynska@poczta.umes.lublin.pl 